HUMANIKA Vol. 19 No. 1 (2014) ISSN 1412-9418

Representasi Kolonisasi Terhadap Masyarakat Kulit Hitam

Hadiyanto

\title{
REPRESENTASI KOLONISASI TERHADAP MASYARAKAT KULIT HITAM AFRIKA DALAM NOVEL THINGS FALL APART KARYA CHINUA ACHEBE
}

\author{
Hadiyanto \\ Fakultas Ilmu Budaya Universitas Diponegoro \\ J1. Prof. H. Soedarto, SH Tembalang Semarang 50275 \\ Email: hadiyanto_smg@yahoo.co.id
}

\begin{abstract}
This article discusses white-skinned race colonization and its impacts on African black-skinned race tribal society and culture in African Anglophone novel Things Fall Apart written by Chinua Achebe. The approach used in this research is postcolonial approach by using post-colonial theory to analyze phenomena as well as the implication of the colonizer and the colonized relationship. The result of this research indicates that the coming of white-skinned race colonialists in African Ibo tribe community with their colonization and cultural imperialism is implemented with varied strategies. Those strategies are proven effectively in strengthening whiteskinned race's colonial hegemony in Africa. The white-skinned race colonialists' imperialism results in horizontal conflict and cultural-social disintegration in African native society; between the pro-colonial and the anti-colonial. Anti-colonial resistence is shown by most African native society to fight against colonial government arrogance and to resist white-skinned race imperialism in Africa.
\end{abstract}

Keywords: African black-skinned race traditional culture, white-skinned race colonization, horizontal conflict, social-cultural disintegration

\section{PENDAHULUAN}

Teks sastra selepas masa kolonialisme dalam perspektif poskolonial sastra, mengekspresikan bagaimana intensnya ñYang Terjajahò menunjukkan perjuangan dan karakter resistensinya. Tulisanï tulisan dalam teks karya sastra yang dihasilkan pengarang pribumi pascakolonialisme seperti novel Things Fall Apart (selanjutnya disingkat TFA) yang ditulis sastrawan Afrika, berusaha mengakomodasi dan memberikan pondasi pijakan yang kuat bagi kultur pribumi masyarakat jajahan. Karakter kental yang diungkapkan di dalamnya menunjukkan bahwa setiap kebudayaan yang dimiliki masyarakat tribal sekalipun akan dipertahankan matiï matian oleh pemiliknya. Fenomena kultural Afrika, kolonialisme, dan resistensi antikolonialisme dalam novel TFA tersebut menarik untuk dikaji dengan perspektif poskolonial. 
Things Fall Apart, yang dalam bahasa Indonesia berarti Segalanya Berantakan, sering didengungdengungkan sebagai salah satu pelopor teks kesusasteraan poskolonial (McLeod, 2000: 130). TFA adalah novel karya Chinua Achebe yang begitu spesifik dan sangat tipikal meng-gambarkan latar kehidupan tradisional dan kebudayaan primitif suku Ibo di Umuofia, Nigeria, Afrika serta responnya terhadap kedatangan kolonialis ras kulit putih bangsa Inggris dari daratan Eropa di akhir tahun 1880. TFA mengisahkan kehidupan suku Ibo yang dipimpin oleh seorang kepala suku yang dipilih masyarakat sukunya karena prestasi, keberanian dan kemenangannya dalam ilmu bela diri, nilai keberhargaan kepribadian serta kontribusi dirinya untuk kemajuan dan keharuman nama suku Ibo Afrika.

Seorang pemuda bernama Okonkwo di usia yang masih sangat muda dinobatkan sebagai pemimpin besar suku Ibo karena prestasinya yang mengagumkan memenangi pertandingan bela diri gulat saat melawan seorang petarung yang lama tidak pernah terkalahkan. Prestasi demi prestasi gemilang dalam kepemimpinannya diraihnya, ia menjadi seorang petarung wrestler berbakat, prajurit suku terbaik, petani yang kaya, anggota suku ternama dan peraih gelar sosial kehormatan suku. Sampai suatu hari ia harus dihukum menjalani pengasingan selama (7) tahun akibat membunuh seorang lelaki muda anggota suku. Setelah berakhirnya masa hukumannya, ia melihat perpecahan dalam sukunya akibat pengaruh kedatangan ras kulit putih Inggris beserta misionaris kolonialnya yang telah mengintervensi adat istiadat, budaya, dan tradisi kehidupan kesukuan masyarakat pribumi dengan menyebarkan ideologi agama baru, mendirikan berbagai fasilitas publik, membentuk pemerintahan dan peradilan kolonial.

Akibat pendudukan kolonialis ras kulit putih Inggris di Afrika dan penyebaran agama baru oleh misionaris kolonialnya, muncullah (2) kelompok masyarakat pribumi, yaitu kelompok pro-kolonial dan antikolonial. Segalanya benar-benar menjadi berantakan di wilayah pribumi suku Ibo itu, bukan kedamaian dan kemajuan pola pikir masyarakat pribumi dengan peradaban yang dibawa kaum pendatang tersebut, tetapi konflik dan pertikaian yang kian hari kian memuncak baik antara masyarakat pribumi dan kolonialis ras kulit putih Inggris maupun antaranggota suku itu sendiri. Konflik, perseteruan, dan kekacauan itu terjadi karena para kolonialis Inggris berambisi menguasai sendi-sendi kehidupan tribal Afrika dengan mediasi penyebaran ideologi agama baru sebagai strategi awal mencengkeramkan hegemoni kolonialnya.

Dalam pandangan kolonialis ras kulit putih Eropa, Afrika dengan komunitas ras kulit hitamnya, sistem kebudayaan tradisional, sistem kepercayaan kepada para dewa, serta pengagungan keyakinan terhadap sesuatu sebagai pembawa keberuntungan dan sebagainya, dianggap lebih rendah derajatnya, primitif dan terbelakang peradabannya dibandingkan orang kulit putih Eropa. Resistensi anti-kolonial radikal ditunjukkan oleh tokoh utama 
HUMANIKA Vol. 19 No. 1 (2014) ISSN 1412-9418

Representasi Kolonisasi Terhadap Masyarakat Kulit Hitam

Hadiyanto

Okonkwo dan orangï orang suku Ibo yang masih memiliki loyalitas kultural, dan penghujung novel itu diakhiri dengan kematian tragis tokoh Okonkwo akibat sikap antikolonialnya dalam memper-tahankan idealisme, ideologi dan nilai-nilai budaya pribumi suku Ibo yang telah dikolonisasi ras kulit putih bangsa Inggris.

\section{METODE}

Berdasarkan tema novel Things Fall Apart yang sarat dengan penjajahan terhadap kultur kehidupan masyarakat tradisional dan reaksi perlawanannya terhadap pendudukan kaum kolonial, maka penulis meneliti karya tersebut dengan pendekatan poskolonial. Pendekatan poskolonial mengkaji segala fenomena ñpenjajahò dan ñterjajahò dalam karya sastra (Endraswara, 2003: 178). Karyaï karya sastra setelah masa kolonial yang mencerminkan koloni-alisme, baik lama maupun baru dapat ditelaah dengan perspektif poskolonial. Ciri khas poskolonial adalah bahwa objek teks berkaitan dengan wilayah bekas jajahan imperium Eropa (Ratna, 2004:220).

Metode pengumpulan data dilakukan terhadap objek penelitian novel Anglophone Afrika Things Fall Apart dengan memanfaatkan penelitian kepustakaan (library research), yaitu penelitian yang dilakukan di ruang kerja peneliti atau di perpustakaan tempat peneliti memperoleh data dan informasi tentang objek penelitiannya melalui buku-buku atau alat-alat audiovisual lainnya (Semi, 1993:8). Pemanfaatan metode kepustakaan ini dilakukan mengingat dataï data yang digunakan dalam penelitian ini seluruhnya diperoleh dari novel tersebut, sedang sumber tertulis atau pustaka seperti; buku, ensiklopedia, esei, jurnal, artikel, majalah, surat kabar, dan sebagainya difungsikan sebagai referensi penunjang.

\section{PEMBAHASAN}

Novel Anglophone Afrika Things Fall Apart (TFA) karya Chinua Achebe secara spesifik merepresentasikan kehidupan tradisional dan meng-ungkapkan kedatangan ras kulit putih Inggris dari daratan Eropa yang dilanjutkan dengan program kolonisasi serta imperialisme budaya di Afrika. Dengan kekhasan kebudayaan pribumi ras kulit hitam Afrika, suku Ibo Afrika dalam TFA dengan kehidupan keseharian masyarakatnya yang ter-golong masih primitif dan marginal, mendorong kaum kolonial kulit putih Inggris Eropa dengan peradabannya yang lebih modern meluaskan wilayah imperial dan hegemoni kolonialnya di Afrika. Program kolonisasi dan imperialisme budaya dicanangkan secara perlahan dan bertahap oleh kolonialis kulit putih Inggris. Dengan motif dan dalih memperadabkan kehidupan primitif tradisional suku Ibo, kolonialis Inggris yang memiliki kepentingan hegemoni kolonial menduduki tanah pribumi Afrika melalui strategi kolonial yang sangat halus, pandai, dan damai. Program kolonisasi dan imperialisme budaya bangsa Inggris pada awalnya ñdicengkeramkanò melalui strategi ideologi, yaitu penyebaran ideologi agama baru dan ditindaklanjuti dengan 
berbagai strategi kolonial lainnya seperti memberikan fasilitas pendidikan, sekolah, dan pusat perdagangan.

\section{A. Konflik Horizontal dan Disintegrasi Sosial Budaya}

Harga mahal yang harus dibayar mahal masyarakat pribumi ras kulit hitam suku Ibo Afrika akibat pendudukan kolonial ras kulit putih Eropa dan kebijakan pemerintahannya adalah meretaknya rasa persatuan kesukuan pribumi Afrika yang sebelumnya memiliki satu keyakinan dan budaya. Perpecahan dalam masyarakat suku Ibo tidak lagi dapat dihindarkan sejak misionaris kolonial mendapat pengikut pribumi, benihbenih konflik horizontal dan disintegrasi sosial-budaya muncul mulai dari lingkup terkecil sampai lingkup yang lebih besar, seperti antarsesama anggota keluarga, antara keluarga yang satu dan keluarga yang lain, antara satu kelompok masyarakat yang satu dan yang lain, dan seterusnya.

Peran kepandaian kaum kolonial ras kulit putih Inggris menundukkan budaya lokal yang dianggap primitif melalui mediasi ideologi agama itulah yang pada akhirnya menyulut disintegrasi budaya suku Ibo, mereka merebut hati saudara, keluarga, dan kerabat lainnya agar meninggalkan tradisi lama dan pindah ke budaya kaum kolonial, sehingga masyarakat suku Ibo bukan lagi satu kesatuan kultural, tetapi suku yang telah terdisintegrasi menjadi (2) kelompok yang saling bertikai.

Segalanya benar-benar menjadi berantakan setelah pendudukan kolonialis kulit putih Eropa, bukan kedamaian yang tercipta, melainkan kekacauan dan pertikaian dalam suku Ibo yang terjadi. Kenyataan seperti itu memicu terciptanya dikotomi biner yang tajam di kalangan penduduk pribumi, antara yang pro-kolonial dan yang anti-kolonial, simpati dan antipati, menerima dan menolak, sehingga muncullah (2) kubu yang saling memiliki kepentingan berbeda dan masing-masing berusaha mempertahankan serta melindungi eksistensi kepentingannya. Masyarakat pribumi yang anti-kolonial menentang kolonisasi ras kulit putih Inggris secara ekstrem dan menginginkan penjajah secepatnya meninggalkan tanah pribumi ras kulit hitam Afrika, karena keberadaan penjajah Eropa itu mengakibatkan konflik horizontal antarsesama komunitas suku Ibo. Sedang sebagian masyarakat suku Ibo yang berpihak terhadap agama baru mendukung kebijakan pemerintahan kolonial Inggris di tanah pribumi Afrika. Masyarakat pribumi prokolonial yang telah mengikuti ideologi agama baru berpendapat bahwa tradisi budaya suku Ibo adalah jelek karena telah ketinggalan zaman, sehingga layak ditinggalkan dan beralih ke corak budaya baru.

\section{B. Masyarakat Pribumi Pro- Kolonial \\ 1. Kelompok Anak Muda \\ a. Nwoye}

Dalam kategori kelompok anak muda pro-kolonial terdapat seorang anak muda bernama Nwoye, ia putera Okonkwo petinggi suku Ibo Afrika. Nwoye perlahan-lahan namun pasti mulai tertarik dengan ideologi agama baru yang ditebarkan oleh misionaris kolonial, karena konsep ideologi agama baru tersebut mengajak umat manusia meninggalkan Tuhan-Tuhan 
HUMANIKA Vol. 19 No. 1 (2014) ISSN 1412-9418

Representasi Kolonisasi Terhadap Masyarakat Kulit Hitam

Hadiyanto

palsu seperti patung-patung kayu dan batu yang disembah oleh penduduk pribumi Afrika. Di samping itu, Nwoye merasa tersentuh dengan alunan lagu renungan di bait puisi agama baru yang penuh peduli mempertanyakan nasib saudarasaudara sekandung sesuku yang dibuang hidup-hidup di semak-semak hutan akibat terlahir kembar dan ia pun teringat kembali ketika Ikemefuna saudara angkatnya yang harus meninggal dibunuh secara tragis di tangan orang tua dan orang-orang suku Ibo lainnya.

Nwoye sangat tidak peduli dengan konsep ketuhanan agama baru karena ia tidak mengerti dengan hal tersebut. Namun demikian, perasaan berempati kepada umat manusia atau rasa kasih sayang kepada sesama yang diajarkan agama baru itulah yang menyentuh hati Nwoye. Perjuangan Nwoye menuju agama baru sangat luar biasa, ia mulanya merahasiakan ketertarikannya terhadap agama baru, kemudian ia mulai berani menampakkan dirinya di tengah kerumunan beribadah bersama pengikut agama baru lainnya setiap akhir pekan, hingga sampai suatu hari keberadaannya diketahui oleh Amikwu, kemenakan Okonkwo, dan fakta itu dilaporkan kepada Okonkwo. Demi agama baru kolonial itu, Nwoye harus rela berkorban menerima kemarahan, ancaman, cekikan, pukulan, dan perlakuan kasar lainnya oleh Okonkwo, orang tuanya sendiri setelah diam-diam menjadi pengikut ajaran agama baru ala kolonial. Perlakuan kasar dan kekerasan fisik harus diterima Nwoye akibat ledakan emosional Okonkwo.

Meskipun telah mendapat perlakuan kasar dari orang tuanya,
Nwoye tidak goyah pendiriannya untuk selalu setia menjadi pengikut agama baru. Secara dramatis komitmen tersebut dibuktikan dengan ketetapan hati Nwoye meninggalkan orang tua serta keluarganya menuju Umuofia tempat misionaris kulit putih mendirikan sekolah kolonial untuk mendidik pengikut pribumi membaca dan menulis. Sebagai seorang anak, Nwoye tidak merasa menyesal telah meninggalkan pergi orang tua serta keluarganya, bahkan ia merasa bahagia dan berjanji akan kembali kepada ibu, saudara laki-laki dan saudara perempuannya sekeluarga untuk beralih keyakinan menuju agama baru yang lebih manusiawi.

Nwoye sebagai pemuda tumpuan masa depan suku Ibo dan harapan Okonkwo, ayahnya, terpaksa harus rela melunturkan loyalitas kulturalnya karena determinasi tinggi terhadap prinsipnya. Ia sadar bahwa Okonkwo, ayahnya, sebagai pemuka suku Ibo tidak akan sejalan dengan pandangan dirinya bahkan menganggap dirinya musuh bukan lagi anaknya. Demikian besar perjuangan dan pengorbanan Nwoye menjadi pengikut agama baru, sehingga ia mendapat kehormatan dari Mr. Brown, misionaris kolonial, dengan dianugerahi nama baru ñIsaacò dan mendapat kehormatan menjalani pelatihan guru kolonial di Umuru.

\section{b. Enoch}

Enoch adalah anak muda pribumi suku Ibo selain Nwoye yang telah meneguhkan hatinya menjadi pengikut agama baru dibawah bimbingan misionaris kolonial, $\mathrm{Mr}$. Brown. Meskipun Mr. Brown tipe misionaris yang sangat toleran, moderat, rendah hati, dan menjaga perasaan penduduk suku pribumi, di 
bawah asuhannya tetap saja muncul orang-orang yang sangat temperamental dan secara emosional sulit dikendalikan, salah satunya adalah Enoch. Enoch pemuda prokolonial yang telah bermimikri seperti kaum kolonial, bersikap frontal dengan berani mengganggu, melecehkan, menghina, dan mencampakkan simbol kesakralan suku Ibo. Ia padahal seorang putera pendeta ternama dari kelompok sekte ular di tanah pribumi suku Ibo Afrika.

Tindakan emosional Enoch yang didasari fanatisme terhadap ideologi agama baru kolonial yang berlebihan mengakibatkan dirinya lupa diri kepada keagungan tradisi budaya suku Ibo, lingkungan tempat ia dibesarkan. Tindakan melecehkan dan menghinakan yang dilakukan Enoch adalah berani menodai simbol kesakralan suku Ibo dengan membunuh dan memakan daging ular piton yang dianggap suci serta dikeramatkan sebagai jelmaan dewa air oleh penduduk pribumi Afrika, sehingga ayahnya yang anti-kolonial dengan keras mengutuknya.

Sikap tersebut menunjukkan bahwa sebagian masyarakat pribumi suku Ibo khususnya para pemuda telah berpindah memberikan integritas, komitmen, loyalitas, serta dedikasinya yang tinggi kepada ideologi dan pemerintah kolonial, bahkan melebihi apa yang dilakukan kolonialis itu sendiri. Enoch memiliki fanatisme agama yang sangat berlebihan sehingga tindakan-tindakannya memicu konflik besar pihak gereja kolonial dan suku Ibo.

Tindakan menghina dan menodai budaya pribumi berikutnya yang dilakukan oleh Enoch karena cintanya kepada ideologi agama kolonial adalah kenekatannya membuka topeng egwugwu di depan publik. Kelompok egwugwu dianggap sebagai titisan roh leluhur yang keramat. Seperti telah diuraikan sebelumnya egwugwu adalah kelompok orang bertopeng yang serupa roh nenek moyang karena diidentikkan dengan reinkarnasinya, mereka memiliki status dan peran strategis tersendiri di setiap desa suku Ibo khususnya dalam ritual tahunan pemujaan dewi bumi.

Egwugwu sangat diagungkan masyarakat suku Ibo, karena keistimewaan keramatnya mereka menganggap bahwa membuka topeng egwugwu di depan publik merupakan salah satu kejahatan terbesar karena wajah mereka pantang dilihat oleh kaum wanita dan anak-anak khususnya, termasuk berbuat atau mengatakan apa saja yang berpotensi menjatuhkan ñkeabadian prestisò egwugwu di mata orang umum. Tindakan nekat yang dilakukan Enoch sebagai pribumi pemeluk agama baru yang pro-kolonial dengan membuka topeng salah seorang egwugwu dalam ritual tahunan adalah kejahatan besar yang menimbulkan aib dan kemarahan yang tidak termaafkan oleh egwugwu. Akibat penghinaan terhadap egwugwu, benih-benih kebencian yang sebelumnya telah tertanam di hati masyarakat pribumi semakin terasa lebih membara dan menyulut konflik lebih besar antara kelompok keramat egwugwu dan misionaris kolonial.

\section{Kelompok Orang Kaya a. Nneka}

Faktor yang lebih berperan memperparah konflik dan disintegrasi adalah semakin bertambahnya kelompok masyarakat kaya dan 
HUMANIKA Vol. 19 No. 1 (2014) ISSN 1412-9418

Representasi Kolonisasi Terhadap Masyarakat Kulit Hitam

Hadiyanto

terhormat suku Ibo yang memiliki pangkat atau gelar sosial mulai menanggalkan atribut identitas keprestisan pangkatnya yang berupa gelang kaki, bergabung menjadi pengikut agama baru, serta berpihak kepada pemerintah kolonial. Salah satu dari masyarakat kaya pro-kolonial pemeluk agama baru itu adalah Nneka, seorang wanita, istri Amadi, seorang petani kaya yang menjadi pengikut agama misionaris karena merasa keberatannya terhadap pembuangan bayi kembarnya setiap kali ia melahirkan demi ketaatannya memenuhi tradisi suku Ibo. Bukti kekritisan Nneka ditunjukkan sebagai penduduk pribumi Afrika terhadap budaya lokal yang mengkonvensikan secara legal pembuangan bayi kembar dan ia menunjukkan fenomena peralihan keyakinannya menuju agama baru.

Penolakan kritis terhadap budaya pribumi suku Ibo yang memberatkan kaum wanita yang melahirkan anak kembar seperti yang dialami Nneka menyuburkan pertumbuhan dan perkembangan ideologi agama baru di tanah pribumi Afrika yang ditandai dengan semakin meningkatnya jumlah pengikut agama baru itu dari ke hari. Sebagai dampaknya, semakin banyak pula masyarakat khususnya kelompok kaum wanita pro-kolonial dan mendukung kebijakan pemerintah kolonial di tanah pribumi suku Ibo Afrika.

\section{b. Ogbuefi Ugonna}

Kelompok orang kaya dan bergelar sosial lainnya yang mengabdikan dirinya kepada ideologi agama kolonial adalah Ogbuefi Ugonna, seorang laki-laki yang telah memiliki (2) gelar sosial penting di suku Ibo. Semangat jiwa pro-kolonial seakan telah mendarah daging di sekujur tubuhnya, sehingga ia memotong gelang kaki sebagai penanda gelar sosial yang dimilikinya dan bergabung dengan agama baru. Fenomena yang sedemikian semakin memperkuat barisan masyarakat pribumi pro-kolonial, terlebih lagi pemerintah kolonial melalui misionarisnya menginstruksikan penganugerahan penghargaan kepada pengikut agama baru dari kelompok masyarakat pribumi pemilik gelar sosial.

Ogbuefi Ugonna mendapat penganugerahan perjamuan suci semacam pesta suci dalam tradisi suku Ibo bersama masyarakat pribumi lainnya karena misionaris kulit putih Inggris merasa sangat bangga dengan perjuangan menuju agama baru yang telah dilakukan Ogbuefi Ugonna. Fenomena tersebut membuktikan bahwa tidak hanya anak muda, orang osu, atau masyarakat tanpa gelar sosial yang menjadi penopang kekuatan kolonial di tanah pribumi, tetapi juga kelompok masyarakat kaya dengan gelar sosial yang sebelumnya memiliki loyalitas kultural tinggi terhadap suku Ibo seperti Ogbuefi Ugonna.

\section{c. Akunna}

Pembesar suku Ibo lainnya yang memiliki loyalitas pro-kolonial karena akhirnya menganut ideologi agama baru adalah Akunna. Akunna merupakan seorang pemuka suku yang kaya dan terhormat di desanya, yang dengan segala kesadaran dan kedalaman pemikirannya mengirimkan salah satu anaknya ke sekolah kolonial di bawah asuhan Mr. Brown. Dengan bantuan Mr. Brown, Akunna berharap agar anaknya menjadi orang pandai terpelajar yang mampu membaca dan 
menulis, sehingga kelak menjadi pemimpin besar yang dapat memajukan masyarakat di tanah pribumi suku Ibo. Mr. Brown sebagai misionaris penyebar agama baru benar-benar bersikap santun menghormati budaya lokal sehingga Akunna sebagai masyarakat pribumi pro-kolonial mempercayakan anaknya ke sekolah kolonial.

Dengan masuknya pembesar suku yang kritis seperti Akunna dalam kelompok masyarakat pribumi prokolonial berarti membawa implikasi semakin merapuhnya sendi-sendi budaya dan semakin parahnya konflik horizontal dan disintegrasi sosial budaya di antara komunitas pribumi suku Ibo Afrika.

\section{Kelompok Orang Osu}

Disintegrasi sosial budaya lebih banyak disebabkan ideologi agama baru yang disebarkan misionaris kolonial itu dianggap sebagai keyakinan humanis dan egaliter, tidak membeda-bedakan strata sosial manusia, sehingga konsep kesamaan derajat manusia tersebut menjadi akses bagi masuknya orang-orang yang tidak berkelas, termasuk keturunan kelompok orang osu atau kelompok masyarakat terbuang yang hidupnya di hutan serta diasingkan jauh dari interaksi sosial oleh masyarakat berkelas sosial dan tradisi adat suku Ibo.

Kelompok orang osu awalnya mencoba memberanikan diri bergabung mengikuti misa di gereja tempat misionaris kolonial memberikan ceramah agama kepada para pemeluk baru, kehadiran mereka disambut hangat oleh Mr. Kiaga, seorang interpreter kolonial dan diperlakukan sebagai saudara sendiri layaknya satu keluarga, sehingga perasaan nyaman, aman, dan damai hidup lekat di hati orang osu. Orang osu yang sebelumnya hidup dalam label sosial yang serba rendah dan terhina bersama seluruh keturunannya, menjadi termanusiakan eksistensi dirinya hingga akhirnya mereka menjadi penganut setia agama baru kolonial.

Ketaatan orang-orang osu terhadap agama baru itu ditandai dengan pemangkasan rambut gembel panjang sebagai identitas ke-osu-an mereka, meskipun awalnya mereka merasa takut dampak pemangkasan rambut itu. Keberanian kelompok orang osu memangkas rambut dan keberpihakan mereka kepada agama kaum kolonial ditunjukkan secara perlahan namun pasti.

Kekuatan masyarakat pribumi pro-kolonial semakin bertambah dengan masuknya kelompok orang osu khususnya di Mbanta. Semakin meningkatnya jumlah pemeluk agama baru dari golongan orang $o s u$ semakin memperdalam jurang konflik horizontal dan disintegrasi sosial budaya di komunitas pribumi suku Ibo. Kebanggaan berlebihan juga terlihat pada diri orang osu setelah menjadi bagian dari aset berharga kaum kulit putih kolonial di Afrika. Mereka menjadi kian berani melakukan tindakan yang menghina kesucian sendi-sendi budaya pribumi seperti, membunuh dan memakan tubuh ular piton yang dikeramatkan suku Ibo. Kelompok orang osu dengan semangat pro-kolonialnya menginjak martabat budaya mereka sendiri seperti yang dilakukan Enoch dan Okoli, sehingga tindakan mereka memicu luapan amarah penduduk pribumi yang anti-kolonial. 
HUMANIKA Vol. 19 No. 1 (2014) ISSN 1412-9418

Representasi Kolonisasi Terhadap Masyarakat Kulit Hitam

Hadiyanto

\section{Masyarakat Pribumi Anti- Kolonial}

\section{Kelompok Pemuka Suku \\ a. Okonkwo}

Okonkwo merupakan tokoh utama novel TFA sekaligus tokoh sentral dalam kelompok pemuka suku Ibo Afrika yang anti-kolonial. Jiwa etnosentrisnya yang tinggi menjadikan dirinya antipati terhadap segala perendahan atau penghinaan supremasi tanah kelahirannya. Kedatangan ras kulit putih Inggris dari daratan Eropa sangat menyinggung harga diri Okonkwo, tindakan mereka menyulut ledakan amarahnya setelah ia melihat pengaruh keberadaan kolonial Inggris, yaitu muncullah (2) kelompok masyarakat antara yang pro-kolonial dan yang anti-kolonial, dan keduanya terperangkap dalam konflik horizontal yang berujung pada disintegrasi sosial dan budaya.

Okonkwo sebagai pemuka suku Ibo yang anti-kolonial sangat berduka melihat realitas sosial terjadi, bukan hanya karena masalah pribadi tentang ñkejahatan pengkhianatan kulturalò puteranya, Nwoye, yang berpindah dalam genggaman agama kaum kolonial, lebih dari itu ia juga sangat terpukul, geram, dan marah dengan kondisi suku Ibo diperbagai pelosok desa yang telah terdisintegrasi, tercerai-berai dalam kehancuran konflik sosial budaya. Sebagai konsekuensi, hubungan sosial Okonkwo dengan anggota masyarakat suku Ibo lain tidak lagi harmonis. Banyak masyarakat pribumi suku Ibo pindah dari tradisi budaya lokal yang lama beralih ke pola tradisi kolonial yang lebih modern, seperti misalnya mengikuti aktivitas belajar membaca dan menulis di sekolah-sekolah kolonial, pengobatan dan penyembuhan penyakit modern di rumah sakit kolonial, bekerja di lembaga-lembaga kolonial, memeluk ideologi agama baru, dan sebagainya. Sikap Okonkwo yang radikal anti-kolonial menentang pendudukan ras kulit putih Eropa juga diperlihatkan kepada temannya, Obierika, ia mengutuk keras laki-laki suku Ibo yang tidak lagi memiliki jiwa perang. Ketegasan Okonkwo ditunjukkan dengan sikap etnosentrisnya yang sangat mengagungkan superioritas suku Ibo dibanding suku lainnya, sehingga implikasinya suku Ibo harus lebih pemberani menentang segala bentuk kolonialisme. Kalimat "we must fight these men and drive them from the land" (Achebe, 1958:151), membuktikan keteguhan sikap dan prinsipnya yang tidak dapat ditawartawar terhadap keberadaan kaum kolonial yang harus diusir paksa dari tanah pribumi.

Puncak sikap radikal antikolonial ditunjukkan Okonkwo, setelah ia diperlakukan sewenangwenang kotma di penjara colonial, dendam kesumat berkobar-kobar ketika ia berhadapan kotma selepas bebas dari penjara. Konsistensi sikap anti-kolonial Okonkwo direalisasikan dengan dipenggalnya kepala pimpinan utusan peradilan kolonial (head messenger) di depan rekan-rekannya yang dengan segala arogansi dan sikap otoriternya memerintahkan pertemuan massal yang digalang Okonkwo dan masyarakat suku Ibo dihentikan.

Keseriusan prinsip radikalisme Okonkwo dalam berjuang melawan kolonisasi Inggris termasuk terhadap kaki tangan kolonialnya. Tindakan resistensi radikal anti-kolonial itu menunjukkan aktualisasi perasaan 
marah, benci, dan dendam kesumat Okonkwo yang sejak lama meledakledak, yang hanya dapat dihentikan dengan pedangnya.

Resistensi anti-kolonial radikal yang dilakukan Okonkwo tentu saja mempunyai konsekuensi yang sangat berat baginya, karena sejak kejadian tersebut ia ditetapkan sebagai target operasi kolonial untuk ditangkap dan dihukum mati. Peristiwa itu pula yang mengakibatkan pemerintah kolonial melalui komisaris wilayah (district commissioner) mengambil kebijakan kolonial yang lebih otoriter, represif, dan tidak manusiawi terhadap penduduk pribumi, khususnya kepada orang-orang yang menentang pemerintah kolonial dan kaki tangannya. Ekses kebijakan kolonial tersebut berupa perlakuan sewenangwenang di bawah tekanan ancaman kolonial bagi masyarakat pribumi.

Komitmen, dedikasi, dan integritas besar Okonkwo demi superioritas dan supremasi suku Ibo meneguhkan dirinya mengakhiri resistensi anti-kolonial dengan memilih jalan yang ditabukan suku Ibo, Okonkwo melakukan aksi bunuh diri dengan menggantung diri di sebuah pohon. Kalimat "Then they came to the tree from which Okonkwo's body was dangling, and they stopped" (Achebe, 1958:178) mempunyai makna semangat resistensi anti-kolonial Okonkwo sampai titik darah penghabisan, akhir kehidupan yang dianggapnya lebih mulia dan bermartabat daripada ditangkap kaki tangan kolonial dan menyerahkan nyawa kepada mereka, meskipun kematian bunuh diri yang sedemikian tragis bertentangan dengan konvensi aturan adat istiadat yang dijunjung tinggi suku Ibo. Hal itu disebabkan dalam sistem kepercayaan suku Ibo, orang yang mati bunuh diri tidak berhak dan bahkan dilarang diperlakukan secara layak oleh keluarga, saudara, atau penduduk suku Ibo lainnya, karena ia dianggap melanggar kehendak dewi bumi sehingga jasadnya sama seperti makhluk halus yang jahat, hanya orang luar suku Ibo yang dapat menyentuh dan menguburkannya.

Posisi strategis Okonkwo sebagai salah satu orang penting dan terhormat di jajaran pemuka suku Ibo tidak menghalanginya memilih jalan kematian tidak terhormat yang melanggar tradisi suku, rela dikubur seperti anjing oleh orang asing yang bukan berasal dari pribumi suku Ibo demi idealisme resistensi antikolonialnya sampai titik darah terakhir menentang kolonisasi dan imperialisme budaya ras kulit putih Eropa.

\section{b. Obierika}

Selain Okonkwo terdapat pemuka suku Ibo Afrika, pemegang keempat gelar sosial suku yang dikategorikan sebagai masyarakat pribumi anti-kolonial, yaitu Obierika, sahabat dekat Okonkwo. Meskipun ia berwatak sopan, toleran, moderat dan lebih halus dari pada Okonkwo yang keras, temperamental dan radikal, Obierika tetap menunjukkan ketidaksenangan dan penentangannya terhadap kehadiran ras kulit putih Eropa yang menjajah masyarakat pribumi.

Prinsip dan sikap anti-kolonial yang ditunjukkan Obierika antara lain dengan selalu memberi informasi tentang perkembangan pendudukan kaum kolonial, mendukung serta memberi kontribusi moral terhadap 
HUMANIKA Vol. 19 No. 1 (2014) ISSN 1412-9418

Representasi Kolonisasi Terhadap Masyarakat Kulit Hitam

Hadiyanto

perjuangan Okonkwo mengusir kolonisasi bangsa Inggris di bumi suku Ibo Afrika. Perjuangan yang dilakukan Obierika juga terlihat ketika bersama Okonkwo menggalang kekuatan massa besar-besaran yang melibatkan seluruh penduduk pribumi suku Ibo Afrika di seluruh (9) desa. Motivasi besar Obierika diperlihatkan dalam berperan aktif mengikuti pertemuan akbar bersama Okonkwo untuk mengusir kaum kolonial ras kulit putih.

Komitmen anti-kolonial Obierika juga diwujudkan dalam bentuk perlindungan menjaga dan membela nama baik Okonkwo ketika sahabatnya telah meninggal dengan pilihan jalan kematian yang ia sukai. Atas dasar sikap antipatinya terhadap kaum kolonial, Obierika rela berkorban diancam dan ditangkap oleh komisaris wilayah serta pasukan pengawalnya untuk dibawa ke meja peradilan kolonial. Walupun Obierika dalam posisi terintimidasi dibawah ancaman kaum kolonial, ia tetap bersikap tenang, mengagungkan nama Okonkwo sebagai salah satu orang besar petinggi suku Ibo yang dihormati penduduk pribumi di hadapan komisaris wilayah, dan memvonis keras komisaris wilayah itu sebagai penyebab kematian tragis Okonkwo, sahabatnya, yang harus dikuburkan seperti seekor anjing. Obierika yang anti-kolonial dan tetap menghormati kematian sahabatnya meskipun bertentangan dengan tradisi kematian terhormat suku Ibo merupakan konsistensi prinsipnya yang tetap dipegang teguh.

Nyali besar Obierika di hadapan kaum kolonial ras kulit putih yang menegaskan bahwa dirinya meskipun tidak seagresif, senekat, dan seradikal
Okonkwo, ia tetap memiliki loyalitas kultural untuk mempertahankan sendisendi kebudayaan pribumi suku Ibo Afrika dari ancaman hegemoni kolonialis Eropa. Pascapenggantungan diri Okonkwo, komisaris wilayah serta anak buahnya tidak berubah sikap dan tindakan arogannya, mereka sewenang-wenang membawa paksa penduduk pribumi suku Ibo Afrika yang tidak bersalah ke peradilan kolonial.

\section{Kelompok Pendeta}

Dalam kategori pendeta agung yang memiliki keahlian supranatural sebagaimana layaknya ñorang pintarò yang mampu meramal masa depan atau sesuatu, terdapat nama Chielo, pendeta perempuan yang menjadi kepercayaan serta jalan perantara bagi penduduk pribumi suku Ibo Afrika yang menginginkan berkonsultasi spiritual atau segala permasalahan ketidakberuntungan nasib hidup kepada pemimpin para pendeta, yakni pendeta Agbala. Teks tidak secara langsung menjelaskan penentangan frontal pendeta Chielo terhadap pendudukan kaum kolonial, tetapi secara tersirat berdasarkan kata-kata pedas yang diucapkannya menunjukkan bahwa pendeta Chielo dan pemimpin para pendeta supranatural, Agbala, yang tinggal di gua perbukitan itu memiliki sikap antikolonial yang dalam. Hal tersebut diperkuat dengan ucapan pendeta Chielo dalam kutipan berikut, "Chielo, the priestess of Agbala, called the converts the excrement of the clan, and the new faith was a mad dog that had come to eat it up" (Achebe, 1958:179). 
Kutipan tersebut menunjukkan bahwa Chielo, pendeta di bawah naungan Agbala, menyebut penduduk pribumi suku Ibo yang telah beralih ke ideologi agama baru seperti kotoran atau sampah suku, sedangkan keyakinan agama baru yang ditebarkan kaum kolonialis Inggris itu sendiri bagaikan anjing rakus yang akan memakan habis keyakinan tradisional kebudayaan suku Ibo Afrika. Dengan demikian dapat disimpulkan bahwa Chielo, sebagai representasi titah pendeta Agbala, termasuk kelompok pendeta anti-kolonial yang menyerukan perlawanan dan pengusiran terhadap para kolonialis Eropa di bumi Afrika.

Para pendeta yang dianggap memiliki kekuatan supranatural tidak hanya di wilayah Umuofia saja, tetapi di setiap wilayah suku lain seperti Abame, tetangga sebelah suku Ibo Afrika. Pendeta di Abame menyatakan dengan tegas bahwa kehadiran ras kulit putih Inggris di wilayah pribumi adalah mimpi buruk karena mereka akan menjadi sumber kejahatan besar di tanah kelahiran penduduk Abame seperti terlihat dalam kutipan berikut, "A great evil come upon their land as the Oracle had warned" (Achebe, 1958:179). Pernyataan para pendeta suci di berbagai wilayah suku itu semakin memperjelas bahwa kelompok pendeta suku sesungguhnya memiliki komitmen anti-kolonial luar biasa menentang kolonisasi dan imperialisme budaya bangsa Inggris di Afrika.

\section{Kelompok Egwugwu}

Egwugwu, seperti telah dijelaskan sebelumnya, adalah kelompok orang dalam suku Ibo yang dianggap serupa atau representasi dari para leluhur yang telah meninggal. Dengan posisi strategis sebagai kelompok khusus di lingkungan masyarakat pribumi suku Ibo, para egwugwu memiliki otoritas sebagai mediator pertikaian antarwarga suku, melindungi, sekaligus menghukum masyarakat pribumi dari orang-orang atau kelompok tertentu yang dianggap sebagai ancaman berbahaya atau merusak tatanan nilai-nilai tradisi lokal pribumi. Egwugwu membuktikan integritas dan dedikasinya sebagai pelindung suku dengan sikap antikolonialnya ketika pemerintah kolonial Inggris melalui misionaris dan pengikutnya melecehkan budaya pribumi.

Pengikut ideologi agama baru, Enoch, dengan segala keangkuhannya mengatakan bahwa para egwugwu tidak akan pernah berani menyentuh kaum Kristiani, lebih dari itu ia nekat membuka topeng sakral yang dikenakan salah satu egwugwu sehingga menyulut api amarah para egwugwu untuk menuntut balas. Misionaris kolonial di bawah kepemimpinan Mr. Smith dianggap orang yang paling bertanggung jawab oleh para egwugwu karena ia sumber penyebab terjadinya ñaib kulturalò tersebut. Penghinaan dan penodaan yang dilakukan Enoch kepada para egwugwu, simbol patron tradisi budaya suku Ibo, adalah akibat ideologi agama baru yang ditebarkan ras kulit putih Inggris melalui misionaris kolonialnya. Perlawanan menentang pendudukan kolonial dilakukan Ajofia, 
HUMANIKA Vol. 19 No. 1 (2014) ISSN 1412-9418

Representasi Kolonisasi Terhadap Masyarakat Kulit Hitam

Hadiyanto

pemimpin egwugwu, dengan menawarkan pilihan dilematis kepada Mr. Smith, misionaris kolonial baru, dan seluruh pengikutnya di gereja kolonial lainnya.

Negosiasi egwugwu yang memberikan opsi sulit untuk dipilih di pihak misionaris kolonial yaitu pertama, Mr. Smith sebagai misionaris kolonial dipersilahkan pergi meninggalkan gereja secara baik-baik atau kedua, misionaris kolonial hidup damai bersanding di tengah-tengah masyarakat suku Ibo dengan mengikuti dan menghormati cara hidup masyarakat pribumi. Misionaris kolonial itu pun diperbolehkan tinggal di komunitas suku Ibo dan menyembah Tuhannya tanpa perlu melakukan aktivitas peribadatan di gereja.

Keberadaan gereja dan sekolah kolonial dianggap sumber penumbuh penghinaan dan penodaan sendi-sendi kultural pribumi Afrika, pemicu petaka konflik horizontal, dan disintegrasi masyarakat suku Ibo, sehingga bangunan gereja kolonial tersebut harus dihancurleburkan hingga rata dengan tanah. Sikap Ajofia dan egwugwu lainnya sebenarnya telah menunjukkan toleransi yang tinggi sebagai masyarakat primitif, mereka tidak menginginkan adanya kekerasan dan pertumpahan darah terjadi di salah satu pihak akibat kemarahan para egwugwu.

\section{SIMPULAN}

Strategi hegemoni kolonial yang diterapkan kolonialis ras kulit putih Eropa dalam TFA itu ternyata efektif membuahkan hasil karena dianggap mampu mengambil hati sebagian rakyat pribumi suku Ibo dari hari ke hari. Untuk menjaga keamanan kepentingan kolonial, selanjutnya kolonialis Inggris menindaklanjuti program kolonisasi dan imperialisme budayanya dengan strategi represif sebagai benteng pelindung pengamanan dari ancaman masyarakat pribumi, berupa pembentukan pemerintahan, peradilan, penjara, komisaris wilayah, kotma atau polisi peradilan, tentara, dan penjara. Dengan strategi represif itulah kepentingan kolonial yang berupa aset ñpenganut agama kolonialò yang berasal dari penduduk pribumi dilindungi dan segala bentuk resistensi anti-kolonial masyarakat pribumi dibasmi.

Keberpihakan pemerintah kolonial mulai muncul dengan adanya penangkapan paksa, penjatuhan hukuman penjara maupun hukuman gantung kepada masyarakat pribumi yang berseberangan dengan ideologi agama kolonial atau setidaknya membahayakan pemerintah kolonial di masa mendatang. Pendudukan kolonialis Inggris di tanah pribumi suku Ibo dengan mediasi ideologi agama tersebut lambat laun mengakibatkan konflik horizontal dan disintegrasi sosial-budaya di kalangan masyarakat pribumi suku Ibo itu sendiri. Masyarakat pribumi suku Ibo 
terpecah ke dalam (2) kategori kelompok besar yang saling bertikai, antara masyarakat pro-kolonial dan masyarakat anti-kolonial, sebagian berpihak dan sebagian yang lain menentang pemerintah kolonial.

Kondisi sosial yang sedemikian kacau dan berantakan akibat kolonisasi dan imperialisme budaya kolonialis Inggris mendorong Okonkwo, pemuka-pemuka suku, dan masyarakat suku Ibo lainnya yang masih mempunyai integritas, loyalitas, komitmen, dan dedikasi terhadap martabat suku, menggalang kekuatan melakukan perlawanan menentang kolonisasi dan imperialisme budaya ras kulit putih Eropa.

\section{DAFTAR PUSTAKA}

Achebe, Chinua. (1958). Things Fall Apart. Everymanôs Library, London: David Campbell Publishers Ltd.

Aschcroft, Bill., et al. (2003). Menelanjangi Kuasa Bahasa: Teori dan Praktik Sastra Postkolonial. Terjemahan Fati Soewandi \& Agus Mokamat. Yogyakarta: Qalam.

Bhabha, Homi K. (1994). The Location of Culture. London and New York: Routledge.

Budianta, Melani. (2003). Membaca Sastra: Pengantar Memahami Sastra untuk Perguruan Tinggi. Magelang: Indonesia Tera. (2004). Teori PosKolonial dan Aplikasinya Pada Karya Sastra. Bandung.
(2005). Pelatihan Kritik Sastra Postkolonial. Departemen Susastra, Fakultas Ilmu Budaya, Jakarta: Universitas Indonesia.

Damono, Sapardi Djoko. (2005). Kenapa Tak Kau Pahat Binatang Yang Lain: Kumpulan Cerpen Afrika. Magelang: Indonesia Tera.

Endraswara, Suwardi. (2003). Metodologi Penelitian Sastra: Epistemologi, Model, Teori, dan Aplikasi. Yogyakarta: Pustaka Widyatama.

Jusuf, Nini Hidayati. (2003). Pengaruh Kolonisasi Perancis dalam Kehidupan Pribadi dan Sosial di Vietnam dalam Dua Novel Francophone UBCP dan MB. Jakarta: Universitas Indonesia.

Loomba, Ania. (2003). Kolonialisme/ Pasca Terjemahan Kolonialisme. Hadikusumo. Yogya-karta: Bentang Budaya.

McLeod, John. (2000). Beginning Postcolonialism. UK: Manchester University Press.

Nurgiyantoro, Burhan. (2005). Teori Pengkajian Fiksi. Yogyakarta: Gadjah Mada University Press.

Owomoyela. (2003). African Literature. Microsoft Encarta @2003

Potter, James L. (1967). Elements of Literature. New York: The Oddyssey Press Inc. 
HUMANIKA Vol. 19 No. 1 (2014) ISSN 1412-9418

Representasi Kolonisasi Terhadap Masyarakat Kulit Hitam

Hadiyanto

Ratna, Nyoman Kutha. (2004). Teori, Metode, dan Teknik Penelitian Sastra. Yogyakarta: Pustaka Pelajar.

Semi, Atar. (1993). Metode Penelitian Sastra. Bandung: Angkasa Publishing.
Sutrisno, Mudji., et. al. (2004). Hermeneutika Pascakolonial: Soal Identitas. Yogyakarta: Kanisius.

Wellek, Rene., et. al. (1956). Theory of Literature. New York: Harcourt Brace \& Co. Publisher. 